\title{
Body Mass Index and Waist Circumference Affect Lipid Parameters Negatively in Turkish Women
}

\author{
İsmail Özkaya ${ }^{1, *}$, Işıl Bavunoglu², Aydın Tunçkale ${ }^{2}$ \\ ${ }^{1}$ Kırklareli University Health School, Department of Nutrition and Dietetics \\ ${ }^{2}$ İstanbul University, Cerrahpaşa Medical School, Department of Internal Medicine, Division of General Internal Medicine \\ *Corresponding author: dytismail@hotmail.com
}

Received August 13, 2014; Revised November 14, 2014; Accepted November 20, 2014

\begin{abstract}
Study Design: Obesity prevalence is incresing in Turkish population whose lipoprotein profile is characterised by low levels of HDL cholesterol. Our study aims to determine how obesity changes lipid profiles in Turkish women. Materials and Methods: We evaluated 2501 overweight and obese adult women. After systemic physical examination and some antropometric studies, blood samples have been analysed for lipid parameters. Results: Body mass index (BMI), trigliserides (TG), very low density lipoprotein-cholesterol (VLDL-C), nonhigh density lipoprotein-cholesterol (NHDL- C), TG/HDL-C ratio, total cholesterol (TC)/HDL-C ratio and LDL-C/HDLC ratio are significantly increased $(p<0,05)$, but HDL-C levels are significantly decreased $(p<0,05)$ in study population. There was a negative correlation between HDL-C and BMI, waist circumference, TG and homeostasis model assessment-insulin resistance (HOMA-IR) $(\mathrm{p}<0,05)$. On the other hand, there was a positive correlation between HDL-C with age, TC $(\mathrm{p}<0,05)$ and between abdominal circumference with TG, NHDL-C, TG/HDL-C ratio, TC/HDL-C ratio and LDL-C/HDL-C ratio $(p<0,05)$. Similarly, there was also a positive correlation between BMI with some lipid parameters (TG, VLDL-C, NHDL- C, TG/HDL-C ratio, TC/HDL-C ratio and LDL-C/HDL-C ratio $(\mathrm{p}<0,05)$. The patients are separated into two groups as metabolic syndrome positive (MS+) and negative (MS-) and then compared. HDL-C in MS+ group was significantly lower than MS- group $(\mathrm{p}<0,05)$. Other all parameters in MS+ group were significantly higher than MS- group $(\mathrm{p}<0,05)$. Conclusion: Increase of abdominal circumference and HOMA-IR has a negative effect on lipid parameters. Additionally, BMI has similarly negative effect on some lipid parameters in Turkish women.
\end{abstract}

Keywords: Obesity, waist circumference, lipid and lipoproteins

Cite This Article: İsmail Özkaya, Işıl Bavunoglu, and Aydın Tunçkale, "Body Mass Index and Waist Circumference Affect Lipid Parameters Negatively in Turkish Women.” American Journal of Public Health Research, vol. 2, no. 6 (2014): 226-231. doi: 10.12691/ajphr-2-6-2.

\section{Introduction}

In Turkey, obesity is a very common risk factor in terms of cardiovascular diseases, especially for the Turkish women. In a study made in 2000, it has been estimated that 2,5 millions of men and 5,3 millions of women are actually at the level of obesity as per the criterion of the $>30 \mathrm{~kg} / \mathrm{m}^{2}$ body mass index (BMI) [1]. Along with the rapid increase in the prevelance related to obesity in our country, the prevelance of cardiovascular diseases is also rapidly increasing in a positive correlation [2].

The "Turkish Heart Study (THS)" performed by Mahley et al. and the "TEKHARF" (Cardiac Diseases and Their Risk Factors in Adults in Turkey) study conducted by Onat et al., have suggested that the Turkish people have a unique lipid and lipoprotein profile characterized by a low level of serum HDL cholesterol (HDL-C) $[2,3,4]$. The fact that the low level of HDL-C is, in addition to Turkey, also commonly seen in Turkish people living in Germany and in the United States, has given cause to the consideration that the issue may be, at least in part, of genetic origin [5,6,7].

The total cholesterol (TC)/HDL-C ratio is considered as ischemic heart disease indicator and it is generally called atherogenic index. This index's being 3,5 and less is considered as low risk, whereas its being 4,5 or above is considered as high risk [7].

In addition, the triglycerides (TG)/HDL-C ratio is also considered as insulin resistance indicator and is wanted to be below $3[8,9]$.

Since the Turks have a very low HDL-C level (in more than $70 \%$ of the men, and in approximately $50 \%$ of the women, HDL-C $<40 \mathrm{mg} / \mathrm{dL}$ ) versus their relatively low serum TC levels, their TC/HDL-C ratios are high as well [6].

The reason why the low level of the HDL-C is as significant as this, is that it may be an ischemic heart disease risk factor even for individuals with a low level of TC and TG [10]. However, there are also studies demonstrating that this information is changing and arguing that the low levels of HDL-C is not as low as claimed in the Turkish population. Therefore, the present 
study aims at assessing whether or not there is a unique low level of HDL-C in the Turkish population.

\section{Subjects}

Overweight (BMI $\geq 25$ and $<30 \mathrm{~kg} / \mathrm{m}^{2}$ ) and obese (BMI $\geq 30 \mathrm{~kg} / \mathrm{m}^{2}$ ) women over 18 years of age, who applied to the Istanbul University, Internal Diseases Out patient clinic, have been included in the study prospectively.

In the diagnosis of obesity, the BMI has been applied. The BMI has been calculated by the weight $(\mathrm{kg}) /$ height $^{2}$ (m) formula [13]. Overweight has been determined as $\mathrm{BMI} \geq 25-29.9 \mathrm{~kg} / \mathrm{m}^{2}$ and obesity as BMI $\geq 30 \mathrm{~kg} / \mathrm{m}^{2}$ [11]. Obese women have been classified as obese of the 1st degree (BMI $30-34,9 \mathrm{~kg} / \mathrm{m}^{2}$ ), obese of the 2nd degree (BMI $\geq 35-39,9 \mathrm{~kg} / \mathrm{m}^{2}$ ) and obese of the 3rd degree (BMI $\geq 40 \mathrm{~kg} / \mathrm{m}^{2}$ ). Besides, women with normal weight (BMI <25 kg/m²), who applied for slimming purposes, have been included in the study as control group.

In order to exclude any secondary causes, women with hypothyroidism, nephrotic syndrome, collagen diseases and type 2 diabetes mellitus have been taken out of the study.

\section{Methods}

The study included 2652 women. Informed written consent was obtained from all participants and the study was approved by Institutional Review Board of Istanbul University, Istanbul Medical School. The medical history of the women coming to the out patient clinic has been taken and some anthropometric measurements have been made by means of their physical examination. For biochemical surveys, venous blood samples have been taken from the antecubital area after a night-long fasting (at least 12 hours).

The weight has been measured by means of a classical bascule, and the height by means of a stadiometre. The bascule used featured a measurement precision of $100 \mathrm{~g}$ intervals, and the stadiometre with $1 \mathrm{~mm}$ intervals. The height has been measured while the patient was in her room clothes and shoes off, her back resting at the stadiometre. The patient's heels have been kept parallel and adjacent to each other. During the height measurement, attention has been paid that the orbitameatal line (Frankfurt plan), i.e. the plane combining the ear meatus and the bottom of the orbita cavity, was parallel to the floor, that the heel, gluteus and occiput protrusion rested against the stadiometre. A slight pressure has been applied on the patient's processus mastoides and it has been pulled upward, and thus the patient has been ensured to stand fully upright. The waist circumference has been measured as the narrowest body diameter between the crista iliaca and the arcus costarum, and the hip circumference has been measured as the broadest body diameter over the gluteus maximuses behind and over the pubis in front [12].

TC, HDL-C, LDL-C, TG, glucose and insulin have been determined. The same day, the samples have been analysed at the Istanbul Medical Faculty's Central Biochemical Laboratory. The total cholesterol, HDL-C, triglycerides and glucose have been determined at the
"Modular DPP autoanalyser" (Roche Diagnostics, Mannheim, Germany) device and the "Roche Diagnostics" kits. The insulin measurements have been realized at the "Eleycsys Modular Analytics E170" (Roche Diagnostics, Mannheim, Germany) device by means of the "Roche Diagnostics" kits.

For the determination of the insulin resistence, HOMAIR (homeostasis model assessment-insulin resistance) has been applied.

The formula HOMA-IR = fasting glucose $(\mathrm{mmol} / \mathrm{L}) *$ fasting insulin (mU/L) / 22.5 has been applied for calculation purposes [13].

In the diagnosis of metabolic syndrome (MS), the criteria of the U.S. "National Cholesterol Education Program The Adult Treatment Panel III (ATP III)” have been applied [14]. The positive outcome of three or more of the following criteria has been considered as MS diagnosis:

Women's waist circumference $\geq 88 \mathrm{~cm}$, TG level $\geq 150$ $\mathrm{mg} / \mathrm{dL}$, blood pressure $\geq 135 / 85 \mathrm{~mm} \mathrm{Hg}$, blood glucose level $\geq 100 \mathrm{mg} / \mathrm{dL}$ and serum HDL-C level $\prec 50 \mathrm{mg} / \mathrm{dL}$.

For statistical assessment purposes, the cases have been entered into the "Dbase IV V2.0" (Borland, U.S.A.) programme and have been analyzed by using the commercial statistical programme "SPSS / PC plus V3.0" (Statistical Package for Social Sciences, SPSS Inc, Chicago, Illinois, U.S.A.). All findings were given as average $\pm \mathrm{SD}$ (standard deviation). The difference between the groups has been calculated by means of the "one-way analysis of variance", the matched series t-test and the chi-square test. The significance in the difference between the average values of more than two groups and their standard deviation has been initially controlled by means of the one-way Anova test. This test has also been assessed as a kind of "trend" criterion. In variables, which were considered significant, the comparison of parameters with each other between groups has been examined by means of the Tukey HSD post hoc test. Parameters, which did not display any normal distribution, and which shifted to the right and to the left, have been normalized by log transformation and compared thereupon. The value of significance has been considered as $\mathrm{p}<0,05$.

\section{Results}

A total of 2501 slightly overweight and obese women as well as 151 women of normal weight have been included in the study. 506 of the women were slightly overweight, 811 of the obese women were obese of the first degree, 634 of them were obese of the second degree, whereas 550 of them were obese of the third degree.

The demographic characters of our study groups have been displayed in Table 1. The more the BMI increases in our study group, the more increases age, weight and waist circumference, whereas the height decreases.

In Table 2, the results of the metabolic risk factors are displayed as per the groups. Accordingly, it is observed that the more the BMI value increases, the more the glucose, systolic blood pressure, diastolic blood pressure, uric acid, insulin and HOMA-IR levels increase $(\mathrm{p}<0.05)$.

Some lipid and lipoprotein parameters related to the study groups are shown in Table 3 . It has been determined that the VLDL-C, nonHDL-C (NHDL-C), TG/HDL-C 
ratio, TC/HDL-C ratio and LDL-C/HDL-C ratio increases with the increment of BMI, whereas the HDL-C level decreases $(p<0.05)$. Besides, it has been seen that while the TC/HDL-C ratio in the normal-weight group was 3.65 \pm 1.3 , it displayed an increment along with the increase in the BMI and that it has increased up to $4,47 \pm 1,3$ in the obese III group $\left(p^{<0.05)}\right.$. Similarly, while the average TG/HDL-C ratio was $1.84 \pm 1.5$ in the normal-weight group, it has been seen that it increased along with the increment of the BMI and that it has increased up to $3.3 \pm$ 1.9 in the obese III group ( $\mathrm{p}<0.05)$.

In accordance with the weight status of the individuals having participated in our study, the HDL-C values vary between 55,6 $\pm 13,7$ and 47,33 $\pm 10,78 \mathrm{mg} / \mathrm{dl}$, whereby the highest values are those of individuals of normal weight and the lowest values are those of the most overweighted group.

Table 4 displays the relations between various variables. Accordingly, while a negative correlation was determined between HDL-C and the BMI, waist circumference, TG and HOMA-IR, a positive correlation was determined between HDL-C and age, TC $(\mathrm{p}<0.05)$. Furthermore, positive correlation was determined between NHDL-C, TG/HDL-C, TC/HDL-C, LDL-C/HDL-C and the BMI, waist circumference, age, TG, TC and HOMA-IR $(\mathrm{p}<0.05)$.

In Table 5, the differences between the lipid variables have been displayed as per the prevelance of the metabolic syndrome of the patients. In women with metabolic syndrome, a significant increase was determined in all variables except for HDL-C, and a significant decrease in HDL-C, in comparison to those without any metabolic syndrome $(\mathrm{p}<0.05)$.

\section{Discussion}

Two main findings emerge in this study. Firstly, the increment of the waist circumference in Turkish obese women has a negative affect both on the HOMA-IR as well as on some lipid variables. Secondly, the increment of the BMI has also affected some lipid profiles negatively. Along with this, it has also been demonstrated that the increase of age affects lipid parameters.

The fact that an increase of the triglyceride levels is determined along with the increment of the waist circumference and the BMI, is similar to the findings in the previous studies $[15,16]$. It has been demonstrated that the difference in the triglyceride levels between individuals of normal weight and of overweight is about $60 \mathrm{mg} / \mathrm{dL}$ in women [17]. Whereas in our study group, this difference has been calculated as $18 \mathrm{mg} / \mathrm{dL}$ in overweight women and between $34-51 \mathrm{mg} / \mathrm{dL}$ in obese ones. In addition, a positive correlation was also determined with the HOMA-IR levels. This finding supports studies showing that insulin resistance causes high triglyceride [18]. The fact that our study did not include any diabetic patient shows that this metabolic change has occured independently from diabetes. In case of the prevelance of insulin resistance, the emission of free fatty acid (FFA) from the fat cell increases. This FFA reaches the liver and here the VLDL-C synthesis is stimulated.
Along with the increase of the waist circumference and the BMI, the HDL-C levels have decreased. Whereby the study conducted by Brown CD et al. has demonstrated that the HDL-C level is affected by weight. Furthermore, in this study, the average of the HDL-C levels in normalweight, overweight and obese women is higher in comparison to our results [19].

Another finding of our study to be emphasized is the fact that the HDL-C level increases along with the increment of age. Though, in the Framingham study it has been clearly demonstrated that the HDL-C level decreases along with the increment of age [20]. We attribute this difference to the fact that diabetic individuals are excluded from the study. Diabetes is a metabolic disease, which causes decrease of HDL-C and the incidence of which increases with age. We are of the opinion that the exclusion of these persons from the study may be the reason for our high level of HDL-C.

In our study group, the TG/HDL-C ratio has been found to be $1.84 \pm 1.5$ in the normal-weight group, it has increased along with the increment of the BMI and the waist circumference, and this ratio has raised up to $3,30 \pm$ 1,9 in obese person of the 3rd degree. The TG/HDL-C ratio has been defined as insulin resistance indicator by various studies $[8,9]$.

Another atherogenic lipoprotein is LDL-C. In the treatment guidelines, LDL-C is determined as first target [21]. While in our normal-weight group, the LDL-C levels were $120 \mathrm{mg} / \mathrm{dL}$, a minimal increment has been demonstrated in overweight and obese women. These findings are similar to the results in the Turkish Heart Study stating that the LDL-C levels of Turkish women have an average value of $99-129 \mathrm{mg} / \mathrm{dL}$ [3]. While the values which we have obtained additionally are less than western countries, they seem close to other studies examining Turkish women [22]. Similarly, there has not been seen any significant change in the LDL-C level parallel to the increment of the waist circumference and the BMI.

Recently, LDL-C/HDL-C ratio has also started to draw attention as much as the LDL-C levels. In the PROCAM study, LDL-C/HDL-C ratio of 5.0, the plasma TG levels being higher than $200 \mathrm{mg} / \mathrm{dL}$ and a HDL-C level below 35 $\mathrm{mg} / \mathrm{dL}$ have been asserted as three major elements being forerunners of the coronary heart disease [23]. In our study, this ratio was 2.29 in the normal-weight group and increased with the increment of the BMI and the waist circumference, and has raised up to 2.81 in obese individuals of the 3rd degree. Besides, there is a significant relation between LDL-C/HDL-C ratio and HOMA-IR. This change may be explained by the decrease of the HDL-C levels upon the increase of the insulin resistance and consequently the decrease of LDL-C/HDLC ratio.

Since the publication of the "NCEP-ATP III" criteria, NHDL has been defined as a new atherogenic lipid parameter [14]. In short, it is a parameter reflecting all cholesterol levels of detrimental effect and constitutes the second treatment target for patients with a high level of triglycerides (i.e. patients with a TG level $\geq 200 \mathrm{mg} / \mathrm{dL}$ ). In our study, the average NHDL-C level in our normalweight group has been found as $139 \mathrm{mg} / \mathrm{dL}$. The more the BMI and waist circumference increased, an increment of the NHDL-C level was seen as well. Similarly, it has also 
demonstrated a positive correlation with HOMA-IR. This circumstance may be explained by the decrease of the HDL-C and consequently the increase of the NHDL-C levels upon the increment of the insulin resistance.

The TC/HDL-C ratio is considered as indicator of the ischemic heart disease and is generally called atherogenic index. It is desired to be equal to 3,5 or less and its being 4,5 or more is considered as a high risk [24]. In our results, the TC/HDL-C ratio in the normal-weight group has been found as $3.65 \pm 1.3$ and has demonstrated an increase in overweight and obese women. Moreover, TC/HDL-C ratio has reached risky values such as $4.47 \pm 1.3$ in obese women of the 3rd degree.

Various researchers have held the prevalence of metabolic syndrome responsible for the lipid disorders seen in obese persons [25]. In our study, it has been expressly seen that the levels of HDL-C have decreased by the prevalence of MS and that, on the contrary, the other lipid variables have increased. This has demonstrated that the change in the lipid parameters in the prevelance of the metabolic syndrome of our results were similar to previous findings.

The relation between obesity and lipid profiles has been examined in many studies. In a study conducted in Iran, it has been demonstrated that the TC, LDL-C and TG levels in obese women were higher than those of normal-weight women, and that, however, their HDL-C levels were lower. Whereas, in central obese women, high triglycerides and low HDL-C levels draw attention [26]. Whereas a Mediterranean study performed in Spain demonstrated that the BMI values do not have any impact on the lipid profile, and that, on the contrary, waist circumference and age is effective [26]. A study made on the U.S. Cherokee Indians demonstrated that obesity in adolescents emerges along with a decrease of HDL-C [27]. We have found a relation between HOMA-IR and the BMI and waist circumference. In that case we may say that in this study group, central obesity is on the foreground when speaking of obesity, because BMI may reflect all obesities, but waist circumference is an indicator of central obesity and has displayed correlation in the same aspect with the BMI.

The trial also has some limitations. In our study, information about the patients' alcohol, cigarette, levels of income, fat and energy consumptions is not available. Therefore, there could not be made any comments on the effects of these factors on the lipid variables and the insulin resistance.

However, our study also has a superiority over the other population studies. This is the fact that those afflicted with hypothyroidism, nephrotic syndrome, collagen diseases and type 2 diabetes, which may affect the lipid metabolism and the insulin resistance, have not been included in the study. It is also possible to interprete these results as a foresight in respect of how the lipid and lipoprotein values of our women population shall be in case type 2 diabetes is eliminated in Turkey.

As a result, increase of abdominal circumference and HOMA-IR has a negative effect on lipid parameters. Additionally BMI has similarly negative effect on lipid parameters in Turkish women.

\subsection{The Authors Declare that They Have no Conflict of Interest}

Table 1. Demographic characters of the study group arranged as per the BMI groups

\begin{tabular}{|c|c|c|c|c|c|c|}
\hline & $\begin{array}{c}\text { Group } 1 \text { (normal } \\
\text { weight) } \\
(\mathrm{n}=151) \\
\end{array}$ & $\begin{array}{c}\text { Group } 2 \\
\text { (overweight) } \\
(\mathrm{n}=506) \\
\end{array}$ & $\begin{array}{c}\text { Group } 3 \text { (obese } \\
\text { I) } \\
(n=811)\end{array}$ & $\begin{array}{c}\text { Group } 4 \text { (obese } \\
\text { II) } \\
(n=634) \\
\end{array}$ & $\begin{array}{c}\text { Group } 5 \text { (obese } \\
\text { III) } \\
(\mathrm{n}=550) \\
\end{array}$ & $\mathrm{p}$ \\
\hline Age (y) & $33,1 \pm 11,0$ & $37,3 \pm 11,4$ & $39,6 \pm 11,2$ & $41,6 \pm 12,0$ & $41,9 \pm 12,1$ & $<0.05^{*}$ \\
\hline Weight (kg) & $57,9 \pm 8,0$ & $71,4 \pm 6,0$ & $81,2 \pm 6,9$ & $92,6 \pm 7,9$ & $111,1 \pm 14,5$ & $<0.05^{*}$ \\
\hline Height (m) & $161 \pm 5,9$ & $159 \pm 6,0$ & $158 \pm 6,0$ & $157 \pm 6,1$ & $156 \pm 6,0$ & NS \\
\hline BMI $\left(\mathrm{kg} / \mathrm{m}^{2}\right)$ & $22,2 \pm 2,5$ & $27,9 \pm 1,4$ & $32,4 \pm 1,4$ & $37,3 \pm 1,4$ & $45,3 \pm 4,8$ & $<0.05^{*}$ \\
\hline $\begin{array}{l}\text { Waist circumference } \\
(\mathrm{cm})\end{array}$ & $73,9 \pm 7,9$ & $85,9 \pm 6,7$ & $94,6 \pm 6,8$ & $103,4 \pm 7,4$ & $115,7 \pm 10,2$ & $<0.05^{*}$ \\
\hline
\end{tabular}

y: year, kg:kilogram, m:meter, cm:centrimeter

*Between group 2,3,4,5 and group 1

Table 2. Metabolic characters of the study group arranged as per the BMI $\left(\mathrm{kg} / \mathrm{m}^{2}\right)$ groups

\begin{tabular}{|c|c|c|c|c|c|c|}
\hline & $\begin{array}{c}\text { Group } 1 \text { (normal } \\
\text { weight) } \\
(\mathrm{n}=151) \\
\end{array}$ & $\begin{array}{c}\text { Group } 2 \\
\text { (overweight) } \\
(n=506) \\
\end{array}$ & $\begin{array}{l}\text { Group } 3 \text { (obese I) } \\
\qquad(\mathrm{n}=811)\end{array}$ & $\begin{array}{l}\text { Group } 4 \text { (obese II) } \\
\qquad(\mathrm{n}=634)\end{array}$ & $\begin{array}{l}\text { Group } 5 \text { (obese } \\
\text { III) }(n=550)\end{array}$ & $\mathrm{p}$ \\
\hline Glucose (mg/dL) & $86,4 \pm 9,0$ & $90,0 \pm 9,1$ & $91,5 \pm 10,2$ & $93,6 \pm 10,9$ & $96,5 \pm 11,9$ & $*$ \\
\hline SBP (mm Hg) & $108,4 \pm 14,8$ & $118,2 \pm 19,3$ & $122,2 \pm 19,2$ & $128,4 \pm 21,3$ & $138,4 \pm 27,5$ & $\dagger$ \\
\hline DBP (mm Hg) & $71,7 \pm 9,1$ & $77,4 \pm 11,3$ & $79,5 \pm 11,7$ & $84,1 \pm 35,2$ & $87,7 \pm 15,8$ & $\S$ \\
\hline Uric acid (mg/dL) & $3,5 \pm 0,9$ & $3,9 \pm 1,0$ & $4,3 \pm 1,0$ & $4,5 \pm 1,1$ & $4,9 \pm 1,2$ & $\theta$ \\
\hline Insulin (mIU/L) & $6,7 \pm 4,3$ & $9,6 \pm 6,7$ & $11,7 \pm 9,2$ & $13,8 \pm 10,2$ & $16,9 \pm 10,8$ & 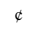 \\
\hline HOMA-IR & $1,4 \pm 1,0$ & $2,1 \pm 1,6$ & $2,6 \pm 2,1$ & $3,2 \pm 2,6$ & $4,1 \pm 2,9$ & $\ddagger$ \\
\hline
\end{tabular}

mg: miligram, dL: deciliter, SBP: Systolic blood pressure, DBP: Diastolic blood pressure, mm Hg: millimeter mercury, mIU: milli international unit, L: liter, HOMA-IR: Homeostasis model assessment-insulin resistance

$*<0.05$ between each groups except group 2 vs group 3

$\dagger<0.05$ between each groups

$\S<0.05$ between each groups except group 2 vs group 3

${ }^{\Theta}<0.05$ between each groups

${ }^{\circledR}<0.05$ between each groups except group 1 vs group 2

$\ddagger<0.05$ between each groups except group 1 vs group 2 
Table 3. Lipid and lipoprotein values of the study group as per the BMI groups

\begin{tabular}{|c|c|c|c|c|c|c|}
\hline & $\begin{array}{l}\text { Group1 (normal weight) } \\
(\mathrm{n}=151)\end{array}$ & $\begin{array}{c}\text { Group } 2 \text { (overweight) } \\
(\mathrm{n}=506)\end{array}$ & $\begin{array}{c}\text { Group } 3 \text { (obese I) } \\
(\mathrm{n}=811)\end{array}$ & $\begin{array}{l}\text { Group } 4 \text { (obese II) } \\
(\mathrm{n}=634)\end{array}$ & $\begin{array}{l}\text { Group } 5 \text { (obese III) } \\
(\mathrm{n}=550)\end{array}$ & $\mathrm{p}$ \\
\hline HDL-C (mg/dL) & $55,6 \pm 13,7$ & $51,2 \pm 11,1$ & $49,1 \pm 11,3$ & $48,1 \pm 11,9$ & $47,3 \pm 10,7$ & * \\
\hline LDL-C (mg/dL) & $120,6 \pm 34,1$ & $128,6 \pm 30,4$ & $126,9 \pm 28,7$ & $129,5 \pm 44,8$ & $127,9 \pm 31,5$ & NS \\
\hline TG (mg/dL) & $93,1 \pm 60,0$ & $110,9 \pm 62,9$ & $126,8 \pm 66,1$ & $133,3 \pm 59,0$ & $144,3 \pm 66,5$ & $\dagger$ \\
\hline VLDL-C (mg/dL) & $18.6 \pm 12.0$ & $22.1 \pm 12.5$ & $25.3 \pm 13.2$ & $26.6 \pm 11.8$ & $28.8 \pm 13.3$ & $\S$ \\
\hline NHDL-C (mg/dL) & $138.8 \pm 53.9$ & $150.2 \pm 7.4$ & $151.8 \pm 8.8$ & $156.0 \pm 39.6$ & $154.7 \pm 36.8$ & $\Theta$ \\
\hline TG/HDL-C & $1.84 \pm 1.5$ & $2.36 \pm 1.6$ & $2.84 \pm 1.9$ & $3.02 \pm 1.7$ & $3.30 \pm 1.9$ & $\mathbb{\$}$ \\
\hline TC/HDL-C & $3.65 \pm 1.3$ & $4,10 \pm 1,3$ & $4.28 \pm 1.2$ & $4.44 \pm 1.2$ & $4.47 \pm 1.3$ & $\ddagger$ \\
\hline LDL-C/HDL-C & $2.29 \pm 1.2$ & $2.62 \pm 1.0$ & $2.71 \pm 0.9$ & $2.84 \pm 1.0$ & $2.81 \pm 1.1$ & J \\
\hline
\end{tabular}

BMI: Body mass index, HDL-C:High density lipoprotein cholesterol, mg: miligram, dL: deciliter, LDL-C:Low density lipoprotein cholesterol,

TG:Triglycerides, VLDL-C:Very low density lipoprotein cholesterol, NHDL-C:Nonhigh density lipoprotein cholesterol, TC:Total cholesterol

$*<0.05$ between each groups except group 3 vs group 4

NS: nonsignificant

$\dagger<0.05$ between each groups except group 3 vs group 4

$\S<0.05$ between each groups except group 3 vs group 4

$\Theta<0.05$ between group 1 vs group 2,3,4

${ }^{\star}<0.05$ between each groups except group 3 vs group 4

$\ddagger<0.05$ between each groups except group 2 vs group 3 and group 3 vs group 4

$\int<0.05$ between each groups except group 2 vs group 3 , group 3 vs group 4,5 and group 4 vs group 5

Table 4. Relations between various parameters

\begin{tabular}{|c|c|c|c|c|c|c|}
\hline & BMI & Waist & Age & TG & TC & HOMA-IR \\
\hline \multirow{2}{*}{ HDL-C } &,- 1462 &,- 1414 & 1359 &,- 3187 & ,1897 &,- 2258 \\
\hline & $\mathrm{p}=, 000$ & $\mathrm{p}=, 000$ & $\mathrm{p}=, 000$ & $\mathrm{p}=, 000$ & $\mathrm{p}=, 000$ & $\mathrm{p}=, 000$ \\
\hline \multirow{2}{*}{ TG } & ,2045 & .2455 & .1807 & & .3938 & ,2859 \\
\hline & $\mathrm{p}=, 000$ & $\mathrm{p}=, 000$ & $\mathrm{p}=, 000$ & - & $\mathrm{p}=, 000$ & $\mathrm{p}=, 000$ \\
\hline \multirow{2}{*}{ LDL-C } & .0223 & .0516 & .2848 & .1980 & .9415 &,- 0044 \\
\hline & NS & NS & $\mathrm{p}=, 000$ & $\mathrm{p}=, 000$ & $\mathrm{p}=, 000$ & $\mathrm{p}=\mathrm{NS}$ \\
\hline \multirow{2}{*}{ NHDL-C } & .0839 & .1228 & .3100 & .4892 & ,9610 & ,0922 \\
\hline & $\mathrm{p}=, 000$ & $\mathrm{p}=, 000$ & $\mathrm{p}=, 028$ & $\mathrm{p}=, 000$ & $\mathrm{p}=, 000$ & $\mathrm{p}=, 000$ \\
\hline \multirow{2}{*}{ TG/HDL-C } & ,1944 & ,2277 & ,0878 & 9097 & ,2364 & ,2940 \\
\hline & $\mathrm{p}=000$ & $\mathrm{p}=, 000$ & $\mathrm{p}=, 000$ & $\mathrm{p}=, 000$ & $\mathrm{p}=, 000$ & $\mathrm{p}=, 000$ \\
\hline \multirow{2}{*}{ TC/HDL-C } & ,1364 & ,1618 & ,1273 &, 5303 &, 5506 & ,1826 \\
\hline & $\mathrm{p}=, 000$ & $\mathrm{p}=, 000$ & $\mathrm{p}=, 000$ & $\mathrm{p}=, 000$ & $\mathrm{p}=, 000$ & $\mathrm{p}=, 000$ \\
\hline \multirow{2}{*}{ LDL-C/HDL-C } & ,0978 & 1170 & 1235 & ,3274 & ,5836 & 1229 \\
\hline & $\mathrm{p}=, 000$ & $\mathrm{p}=, 000$ & $\mathrm{p}=, 000$ & $\mathrm{p}=, 000$ & $\mathrm{p}=, 000$ & $\mathrm{p}=, 000$ \\
\hline
\end{tabular}

BMI: Body mass index, TG:Triglycerides, TC:Total cholesterol, HOMA-IR: Homeostasis model assessment-insulin resistance, HDL-C:High density lipoprotein cholesterol, LDL-C:Low density lipoprotein cholesterol, NHDL-C:Nonhigh density lipoprotein cholesterol

Table 5. Assessment of women with and without metabolic syndrome

\begin{tabular}{ccc}
\hline & No MS n=1495 (\% 56,4) & MS n=1157 (\% 43,6) \\
\hline Age (y) & $37,8 \pm 11,5$ & $42,3 \pm 11,8$ \\
TC (mg/dL) & $195,8 \pm 40,1$ & $209,3 \pm 43,4$ \\
TG (mg/dL) & $96,5 \pm 40,3$ & $166,4 \pm 69,5$ \\
HDL-C (mg/dL) & $53,4 \pm 11,8$ & $43,8 \pm 9,0$ \\
LDL-C (mg/dL) & $122,9 \pm 35,1$ & $132,1 \pm 38,5$ \\
VLDL-C (mg/dL) & $19,3 \pm 8,0$ & $33,2 \pm 13,9$ \\
NHDL-C (mg/dL) & $142,3 \pm 37,9$ & 0,000 \\
TG/HDL-C & $1,92 \pm 0,9$ & 0,000 \\
TC/HDL-C & $3,79 \pm 1,0$ & $4,01 \pm 2,0$ \\
LDL-C/HDL-C & $2,41 \pm 0,9$ & $4,93 \pm 1,3$ \\
Insulin (mIU/L) & $10,37 \pm 7,3$ & $3,12 \pm 1,1$ \\
HOMA-IR & $2,29 \pm 0,7$ & $15,62 \pm 11,3$ \\
Glucose (mg/dL) & $88,6 \pm 8,5$ & 0,000 \\
\end{tabular}

MS: Metabolic syndrome, y: year, TC:Total cholesterol, mg: milligrami dL: deciliter, TG: triglicerides, HDL-C :High density lipoprotein cholesterol, LDL-C: Low density lipoprotein cholesterol, VLDL-C:Very low density lipoprotein cholesterol, NHDL-C: Nonhigh density lipoprotein cholesterol, HOMA-IR: Homeostasis model assessment insulin resistance

\section{References}

[1] Hatemi H, Yumuk VD, Turan N et al. Prevalence of Overweight and Obesity in Turkey. Metabolic Syndrome and Related Disorders 2003; 1: 285-90.

[2] Onat A. Risk Factors and Cardiovascular Disease in Turkey. Atherosclerosis 2001; 156: 1-10.

[3] Mahley RW, Palaoglu KE, Atak Z et al. Turkish Heart Study: Lipids, lipoproteins, and apolipoproteins. J Lipid Res 1995; 36: 839-59.

[4] Mahley RW, Ozbayrakci S, Bersot TP et al. Modulation of high density lipoproteins in a population in Istanbul Turkey with low levels of high density lipoproteins. Am J Cardiol 2005; 96: 547-55.

[5] Luttmann S, von Eckardstein A, Wei W et al. Electrophoretic screening for genetic variation in apolipoprotein C-III: Identification of a novel apoC-III variant, apoC-III (Asp45 $\rightarrow$ Asn), in a Turkish patient. J Lipid Res 1994; 35: 1431-40.
[6] Bersot TP, Vega GL, Grundy SM et al. Elevated hepatic lipase activity and low levels of high density lipoprotein in a normotriglyceridemic, nonobese Turkish population. J Lipid Res 1999; 40: 432-8.

[7] Mahley RW, Pépin J, Palaoglu KE et al. Low levels of high density lipoproteins in Turks, a population with elevated hepatic lipase: High density lipoprotein characterization and genderspecific effects of apolipoprotein E genotype. J Lipid Res 2000; 41: 1290-301.

[8] Wagner AM, Perez A, Sanchez-Quesada Jl et al. Triglyceride to Hdl cholesterol ratio in the dyslipidemic classification of type 2 Diabetes. Diabetes Care 2005; 28: 1798-800.

[9] Shishehbor MH, Hoogwerf BJ, Lauer MS. Association of triglyceride to $\mathrm{Hdl}$ cholesterol ratio with heart rate recovery. Diabetes Care 2004; 27: 936-41.

[10] The Expert Panel. Summary of the second report of the National Cholesterol Education Program (NCEP) Expert Panel on Detection, Evaluation and Treatment of high blood cholesterol in adults. J Am Med Assoc 1993; 269: 3015-23. 
[11] Orgeas MG, Troché G, Azoulay E et al. Body Mass Index. Intensive Care Medicine 2004; 30: 437-43.

[12] Cox BD, Whichelow MI. Ratio of waist circumference to height is better predictor of death than body mass index. Br Med J 1996; 313: 1487-91.

[13] Tunckale A, Aran SN, Karpuz H et al. Relationship between insulin resistance and end-organ damage in white coat hypertension. Am J hypertens 2004; 17: 1011-6.

[14] Expert Panel On Detection Evaluation And Treatment Of High Blood Cholesterol In Adults. Executive Summary Of The Third Expert Panel On Detection, Evaluation And Treatment Of High Blood Cholesterol In Adults (Adults Treatment Panel 3). JAMA 2001; 285: 2486-97.

[15] Fava S,Wilson PWF, Schaefer EJ. Impact of body mass index on coronary heart disease risk factors in men and women The Framingham Offspring Study. Arteriosclerosis, Thrombosis, and Vascular Biology 1996; 16: 1509-15.

[16] $\mathrm{Hu}$

http://eurheartj.oxfordjournals.org/content/25/24/2212.short-aff1Tuomilehto J, Silventoinen $\mathrm{K}$ et al. Joint effects of physical activity, body mass index, waist circumference and waist-to-hip ratio with the risk of cardiovascular disease among middle-aged Finnish men and women. Eur Heart J 2004; 25: 2212-19.

[17] Denke MA, Sempos CT, Grundy SM. Excess Body Weight. An under recognized contributor to dyslipidemia in white American women. Arch Intern Med 1994; 154: 401-10.

[18] Howard BV, Ruotolo G, Robbins DC. Obesity and Dyslipidemia. Endocrinol Metab Clin N Am 2003; 32: 855-67.
[19] Brown CD, Higgins M, Donato KA et al. Body mass index and the prevalence of hypertension and dyslipidemia. Obes Res 2000; 8: 605-19.

[20] Wilson PWF, Anderson K, Hanri T et al. Determinants of change in total cholesterol and HDL-C with age: The Framingham Study. J Gerontol 1994; 49: 252-7.

[21] Mancia G, Fagard R, Narkiewicz K et al. 2013 ESH/ESC Guidelines for the management of arterial hypertension. J Hypertens 2013; 31: 1281-357.

[22] A. Tunckale, S. Aran, S. Tavsanoglu et al. Are serum HDL-C levels of Turkish people really low? Atherosclerosis 2005;6 (Suppl 1): 28

[23] Assmann G, Schulte H. Relation of high density lipoprotein cholesterol and triglycerides to incidence of atherosclerotic coronary artery disease The Procam Experience. Am J Cardiol 1992; 70: 733-7.

[24] Castelli WP, Abbott RD, Mcnamara PM. Summary estimates of cholesterol used to predict coronary heart disease. Circulation 1983; 67: 730-4.

[25] Azizi F, Salehi P, Etemadi A et al. Prevalence of metabolic syndrome in an urban population: Tehran Lipid and Glucose Study. Diabetes Research and Clinical Practice 2003; 1: 29-37.

[26] Mataix J, Lopez-Frias M, Martinez-De-Victoria E et al. Factors associated with obesity in an adult Mediterranean population. Influence on plasma lipid profile. J Am Coll Nutr 2005; 24: 45665.

[27] Blackett PR, Blevins KS, Stoddart M et al. Body mass index and high-density lipoproteins in Cherokee Indian children and adolescents. Pediatr Res 2005; 58: 472-7. 